\title{
Metabolic Syndrome (MetS): A study protocol of health-promotion lifestyle modification intervention
}

\author{
Azaizirawati Ahmad 1,2, Siti Khuzaimah Ahmad Sharoni ${ }^{1}$, Rosuzieta Fauzi ${ }^{1}$, Septa Katmawanti ${ }^{3}$ \\ ${ }_{1}$ Center for Nursing Studies, Faculty of Health Sciences, \\ Universiti Teknologi MARA, Puncak Alam Campus, 42300 Bandar Puncak Alam, Selangor, Malaysia \\ 2 Kota Bharu Medical Centre, Jalan Sultan Yahya Petra, Lundang, 15150 Kota Bharu, Kelantan, Malaysia \\ ${ }_{4}^{4}$ Public Health Department, Faculty of Sport Science, Universitas Negeri Malang, Malang, East Java, Indonesia
}

azaizirawati@kbmc.com.my, sitik123@uitm.edu.my, rosuzeita@uitm.edu.my, septakatma.fik@um.ac.id Tel: 011-55556963

\begin{abstract}
Introducing a healthy lifestyle among young adults enrolled at higher learning institutions via health promotion is best to improve health. This study investigates the effects of lifestyle modification intervention programs (LMIP) on perceived benefit-barrier behaviour, self-efficacy, health-promoting lifestyle behaviour, and MetS parameter. This two-phase study: cross-sectional and two-arm randomized controlled trial involved 124 young adults who full-fill the criteria randomly assigned either intervention or control groups. The intervention group will receive LMIP, while the controlled group will receive an information booklet. Data will be collected at four-time points and analyzed using a mixed-design analysis of variance (ANOVA).
\end{abstract}

Keywords: young adult, cardiovascular diseases, physical activity, diet

eISSN: 2398-4287@ 2021. The Authors. Published for AMER ABRA cE-Bs by e-International Publishing House, Ltd., UK. This is an open access article under the CC BYNCND license (http://creativecommons.org/licenses/by-nc-nd/4.0/). Peer-review under responsibility of AMER (Association of Malaysian Environment-Behaviour Researchers), ABRA (Association of Behavioural Researchers on Asians/Africans/Arabians) and cE-Bs (Centre for Environment-Behaviour Studies), Faculty of Architecture, Planning \& Surveying, Universiti Teknologi MARA, Malaysia.

DOI: https://doi.org/10.21834/ebpj.v6i18.3062

\subsection{Introduction}

Metabolic syndrome (MetS) significantly increases the risk of developing non-communicable diseases (NCDs), mainly cardiovascular diseases (CVDs), due to the presence of dyslipidemia, hyperglycemia, and hypertension. MetS associated with NCDs prevalence are increasing globally (Sakalyan, 2018), and Malaysia has become the second country in the pacific region with the highest prevalence of MetS (37.1\%) (Ranasinghe et al., 2017). Mets is a disorder of energy utilization and storage reflecting underlying insulin resistance. It is characterized by at least three of the following five risk factors: abdominal obesity, high blood pressure, raised fasting blood sugar, high serum triglycerides, and low high-density lipoprotein cholesterol (HDL-C) (WHO, 2010). The latter two is an abnormality in the blood cholesterol value known as dyslipidemia. Cholesterol is a structural component of the plasma membrane, and it is essential for life and has many roles that contribute to normally functioning cells (Huff, Bod \& Jiala, 2020). Therefore, in almost every country, identifying and treating dyslipidemia most of the time will be done among older adults over 40 years old.

Dyslipidemia in young adults is prone to develop risk factors for atherosclerosis and may contribute to coronary heart disease in their future adulthood (Haney et al., 2007). Identifying and preventing the affected youths may reduce long-term cholesterol-related disorders through intervention. Among the general population, young adults enrolled in high learning institutions (HLI) are considered high-risk populations to adopt unhealthy lifestyles due to changes in their study mode and experience of an independent life away from their parents

eISSN: 2398-4287@ 2021. The Authors. Published for AMER ABRA cE-Bs by e-International Publishing House, Ltd., UK. This is an open access article under the CC BYNCND license (http://creativecommons. org/licenses/by-nc-nd/4.0/). Peer-review under responsibility of AMER (Association of Malaysian Environment-Behaviour Researchers), ABRA (Association of Behavioural Researchers on Asians/Africans/Arabians) and CE-Bs (Centre for Environment-Behaviour Studies), Faculty of Architecture, Planning \& Surveying, Universiti Teknologi MARA, Malaysia.

DOI: https://doi.org/10.21834/ebpj.v6i18.3062 
or guidance. Moreover, the young age student may assume that they are in good health and not pay much attention to their future health problem. So, investigating young adults among the HLI student's awareness and behaviour towards a healthy lifestyle may be considered a priority for preventive efforts and management of MetS. As its prevalence increases dramatically with age, identifying and managing its contributing factors has become more prudent. MetS are also known as a complex multifactorial trait that was influenced not just by biological, genetic factors but also by the environment, including lifestyle. Considering the multi-modal approach to managing MetS does not appear to be modifying the subject of non-pharmacological therapy in terms of lifestyle modification such as healthy diet and physical activity. It was suggested that primary intervention is holistic, cost-effective, and increases life quality (Saboya et al., 2016). Health promotion is the best option to improve health by introducing healthy lifestyles and habits to achieve this outcome.

The concept of health promotion is to promote a greater awareness of the positivity towards health by targeting specific populations or communities to develop their skill and knowledge to understand and prevent the forming of other illnesses and accelerate their development (WHO, 2019). However, there is still limited evidence to support the effectiveness of health promotion lifestyle intervention among the young adult population enrolled in $\mathrm{HLI}$ to prevent and manage MetS risk factors.

This study aims to assess the level of knowledge and awareness of MetS, health-perceived behaviour, self-efficacy, and healthpromoting lifestyle behaviour among young adults, especially HLI students. This study also aims to evaluate the pre-and post-effects of health-promoting lifestyle modification intervention programs on blood cholesterol level, body mass index, and MetS parameter for preventing and managing Mets as a risk factor of developing CVDs.

\subsection{Literature Review}

Mets are considered a major complex public health issue due to the associated risk for developing Type 2 Diabetes Mellitus (T2DM) and cardiovascular diseases (CVDs) (Monnerie et al., 2020), which contribute significantly to the burden of disease worldwide (Solomon \& Mulugeta, 2019). Dyslipidemia is regarded as a hallmark of MetS, and over the past five years, the trend of dyslipidemia among Malaysian adults has increased. A previous study reported that $35.1 \%$ of adults aged above 18 years old had high blood cholesterol levels. However, almost half of the number does not become aware of their blood cholesterol status (Rifin et al., 2018). Therefore, adequate literacy levels and awareness are essential, leading to a successful education program. As a result, the individual will have the capacity to understand basic health information, make appropriate health decisions, and engage in health behaviour maintenance in the future. Dyslipidemia affects all stages of the population. Therefore, it is vital to observe trends in different life cycle phases, especially among young adults in $\mathrm{HLI}$ such as college or university.

A previous study on the impact of academic exposure on the health status of university students by Brandao and colleagues (2011) showed a higher rate of dyslipidemia when a trend of total cholesterol and lower (LDL)cholesterol reported an increase in value between academic exposure versus non-academic exposure student (48\% versus $28.6 \%$ ) respectively. A study investigated on risk behaviour of CVDs towards college students around ASEAN countries showed a high prevalence of overweight, low physical activity, tobacco use, binge drinking, and non-avoidance of fat and cholesterol into their meal (Peltzer \& Pengpid, 2018). In Malaysia, previous studies showed that college or university students were not keen on performing the exercise as $10-58 \%$ of their respondents rarely or never did the physical activity (Ibrahim, Rahman \& Rahman, 2016).

\subsection{Health-promotion Intervention of Lifestyle Behavior}

Lifestyle, by definition, is in the way of living, while a healthy lifestyle is a way of living that lowers the risk of being seriously ill or dying at an early age (WHO, 1999). Some diseases are preventable and can be avoided in many deaths, such as coronary heart disease. However, health is not just about preventing illness but also about physical, mental and social well-being. A more positive role model is provided for other people when a healthy lifestyle is adopted. "By the year 2015, people across society should adopt healthier living patterns" this phrase was adopted from European Health Target by the WHO Regional Committee for European in September 1998. Five years ahead by the target year, NCDs had become the number one killer of the population worldwide. CVDs still chart the highest causes of death among the clinical patient due to modifiable risk factors of health behaviour as the significant causes.

Health practitioners who have traditionally concentrated on disease treatment are increasingly concerned with preventing and providing health through promoting lifestyles and removing the factors that have a detrimental effect on human health in every way (Tol et al., 2016). Health promotion is an approach taken to direct people to acquire physical fitness and general well-being. This method of promotion aims to guide individuals to become self-actualized through growing encouragement to participate in health promotion behaviours concerning their human health potential (Walker, Schrist, \& Pender, 1987). When contemplating a personal involvement in health promotion lifestyle, these six domains need to be considered; 1) Nutrition; 2) Physical activity; 3) health responsibility; 4) spiritual growth; 5) Health responsibility, and 6) Stress management (Pander, Murdough \& Parsons, 2010). Health promotion lifestyle is a multi-dimensional pattern of self-motivated attitudes and behaviours that lead to maintaining and promoting their health and self-improvement (Walker et al., 1996). A past study conducted in Iran among university students revealed a statistically significant relationship between life quality and spirituality. However, there was no significant relationship between life quality and nutrition, physical activity, self-health responsibility and stress management (Tol et al., 2016). A similar finding was reported from a study related to health-promoting lifestyle among nursing students in Malaysia. The highest score was revealed in spiritual growth, and physical activity was the lowest (Geok et al., 2014). Table 1 below summarises the previous studies on the effect of a health-promoting behaviour and lifestyle intervention. 
Table 1 Review of previous studies on the effect of a health-promoting behaviour and lifestyle intervention

\begin{tabular}{|c|c|c|c|}
\hline TOPIC & $\begin{array}{l}\text { AUTHORS } \\
\text { (YEAR) }\end{array}$ & COUNTRY & FINDINGS \\
\hline \multirow{3}{*}{$\begin{array}{l}\text { Health-promoting behaviour } \\
\text { and lifestyle among college } \\
\text { or university students }\end{array}$} & $\begin{array}{l}\text { Wang, Xin \& Wu } \\
\text { (2013) }\end{array}$ & China & $\begin{array}{l}\text { A high percentage of students do not exhibit a healthy } \\
\text { lifestyle, health risk behaviour }(p=0.001)\end{array}$ \\
\hline & Geok et al. (2015) & Malaysia & $\begin{array}{l}\text { Student nurses adopted a moderate health-promoting } \\
\text { lifestyle with the highest score in spiritual growth }(2.92 \\
\pm 0.43) \text { but lowest in physical activity }(1.74 \pm 0.39)\end{array}$ \\
\hline & Tong et al. (2016) & Malaysia & $\begin{array}{l}\text { Poor self-perceived on health status and placed low } \\
\text { self-perceived importance of taking health measures }\end{array}$ \\
\hline \multirow[t]{3}{*}{$\begin{array}{l}\text { Effectiveness of lifestyle } \\
\text { intervention on management } \\
\text { of hypercholesterolemia }\end{array}$} & $\begin{array}{l}\text { Mann, Beedie \& } \\
\text { Jimenez (2014) }\end{array}$ & United Kingdom & $\begin{array}{l}\text { Aerobic + Resistance training ( } 1 \text { hour, } 3 \text { times/week, } \\
8 \text { weeks) Significantly reduce TC (from } 203 \text { to } 186 \\
\mathrm{mg} / \mathrm{dL}, \mathrm{p}<0.01 \text { ) and triglycerides (from } 122 \text { to } 91 \\
\mathrm{mg} / \mathrm{dL}, \mathrm{p}<0.05 \text { ) }\end{array}$ \\
\hline & $\begin{array}{l}\text { Anjali \& Sabharwal } \\
(2015)\end{array}$ & India & $\begin{array}{l}\text { Intervention with diet and exercise has proven to be } \\
\text { beneficial in improving lifestyle practices. }\end{array}$ \\
\hline & Brown et al. (2016) & $\begin{array}{l}\text { United States of } \\
\text { America }\end{array}$ & $\begin{array}{l}\text { Lost } 5-10 \% \text { of starting weight showed significant } \\
\text { reductions in total cholesterol, LDL cholesterol, and } \\
\text { triglycerides }(p<0.05)\end{array}$ \\
\hline \multirow{3}{*}{$\begin{array}{l}\text { Effectiveness of health } \\
\text { promotion program on } \\
\text { healthy lifestyle }\end{array}$} & $\begin{array}{l}\text { Wang, Chair \& Wong } \\
\text { (2016) }\end{array}$ & China & $\begin{array}{l}\text { Improving self-efficacy }(p<0.05) \text { and physical aspect } \\
\text { QOL }(p=0.02) \text { among patient with MetS }\end{array}$ \\
\hline & Erenoglu et al. (2019) & Turkey & $\begin{array}{l}\text { Affected health responsibility, interpersonal } \\
\text { communication, health perception, and increase in } \\
\text { self-efficacy levels }(p<0.05) \text { among university } \\
\text { students }\end{array}$ \\
\hline & Zheng et al. (2020) & China & $\begin{array}{l}\text { Improved self-efficacy }(p<0.05) \text { and implementation } \\
\text { of health behavior }(p<0.05) \text { but no significant } \\
\text { changes in blood cholesterol level }(p=0.682) \text {. } \\
\text { Suggested to add an extensive and interactive lifestyle } \\
\text { intervention }\end{array}$ \\
\hline
\end{tabular}

In general, for individuals to change their behaviour towards a healthy lifestyle, they must understand the benefit of a healthy lifestyle and identify the barrier and their capability to engage and enhance the behaviour changes. Guidance would have to be given to set a clear, realistic and achievable target for the expected good outcome following the desired period. Health-promotion lifestyle intervention plays a vital role to achieve the highest possible health outcome to reduce the prevalence of non-communicable diseases, especially CVDs, in the future.

\subsection{Methodology}

The current study is involved Phase 1 as a cross-sectional baseline data collection and Phase 2, an intervention phase for randomized control trial (RCT) to investigate the pre-and post-intervention effects of health-promoting lifestyle modification intervention program.

\section{Phase 1}

This phase involved a quantitative descriptive and cross-sectional study and aims to assess the knowledge and awareness of MetS among $\mathrm{HLI}$ students and identify the relationship between socio-demographic factors, perceived barrier-benefit behaviour, and self-efficacy with health-promoting lifestyle behaviour among HLI students. The finding from this phase will provide valuable information. It help organize the health-promoting lifestyle intervention program during phase 2 to deliver effective interventions to prevent MetS. An online selfadministered questionnaire, anthropometric measurement, and rapid test assessment for blood cholesterol level investigation are performed. One stage cluster random sampling are applied in this phase to select the study location with eligibility criteria were used in this study. The results data from this phase will used to design the program for intervention in phase 2. 


\section{Phase 2}

To address the research objectives, a randomized control trial (RCT) was conducted within 12-week of a health-promoting lifestyle modification intervention program with a pre-and post-test double-arm design (intervention and control group) among young adults enrolling at $\mathrm{HLI}$. The group allocation was determined randomly, where the two groups were allocated to either intervention or control with a probability of 0.5 (Campbell \& Walters, 2014). The participants were analyzed based on the intention-to-treat principle to maintain reliability and internal validity and prevent randomization errors. This phase is a single-blinded study where only the researcher knew the group allocation (intervention or control). The researcher-supported team (e.g., research assistant, statistician) or others involved in this study are unaware of group assignment. The intervention group participants will follow the intervention program for 12 weeks, complete questionnaires, and undergo repeated assessment pre- and post-intervention. The measurement conducted at baseline, week-4 (1st follow-up), week-8 (2nd follow-up), and week-12 (evaluation). Simultaneously, the control group were received an information booklet related to the management of MetS (adopted from the Malaysia Ministry of Health) and undergo the same assessment and measurement. After completing the study, the control group were offered to receive the same program as the intervention group. Simple random sampling were carried out for participant selection. The eligible participants who participated in Phase 1 were chosen, and they had an equal chance of being included in the sample. The randomization of participants into the group were done using Research Randomizer by Urbaniak and Plous (2013) from www.randomizer.org.

\subsection{Research Instrument \\ Questionnaire assessment tools}

The questionnaire assessment tools were consisting of 1) Socio-demographic data; 2) Assessment of knowledge and awareness towards MetS; 3) Assessment of perceived barrier-benefit behaviour; 4) Self-efficacy measurement; 5) Assessment of health-promoting lifestyle behaviours. In addition, an online self-administered questionnaire in the English version were provided through survey software using SurveyMonkey.com.

\section{Intervention Measurement Tools}

During four time-points: at baseline, week-4, week-8, and week-12 of the program, all the selected participants were undergo 1) Anthropometric measurement, 2) Blood pressure measurement, and 3) Blood sample collection for Fasting Lipid Profile and Fasting Blood Sugar.

\subsection{Intervention Program Module}

The lifestyle modification intervention (LMI) program module was follow the Health Promotion Model framework by Nola Pender (1996) and Albert Bandura's self-efficacy theories (1997). The LMI knowledge platform constructs the health promotion model regarding prior related behaviour and personal factors, behaviour-specific cognition, and effects of perceived benefits- barrier behaviour, perceived selfefficacy, and affect cues to behaviour. Within the framework of the health promotion model, the education session included a brief introduction of MetS and its management, assessment of current behaviour and behaviour-specific cognition, providing personalized advice regarding healthy diet, regular exercise, stress management, and self-monitoring, also constructing a plan to make modification behaviour. The intervention is focusing on increasing the participant's cognition for adopting health-promoting behaviours. At the same time, self-efficacy is a crucial behaviour-specific cognitive factor contributing to implementing health-promoting behaviours. To enhance participants' self-efficacy, they are encouraged to develop their target, work in small, realistic steps, focus on their attention, and set the confidence to perform the desired behaviour.

The intervention are provide detailed knowledge related to MetS and practical strategies to implement health-promoting behaviours in daily life. The intervention will be consisted:1) individualized in-person education, 2) grouping activity, 3) a lifestyle modification intervention e-booklet including exercise tools, and 4) virtual follow-up. The LMI program developed through intensive literature review and following the guideline from the 5th edition of Clinical Practices Guideline for Management of Dyslipidemia 2017 (Ministry of Health (MOH)), The National Cholesterol Education Program Adult Treatment Panel III (NCEP ATP III), 2019 European Society of Cardiology (ESC) and European Atherosclerosis Society (EAS) of The Task Force for management of dyslipidemia and WHO for Prevention of CVD. In addition, a panel of experts evaluate the completed LMI module for appropriateness and relevance of content. The content validation will be using an adapted content validation form proposed by Castro and colleagues (2007).

\subsection{Data Collection Process}

After ethical approval by UiTM Research Ethics Committee, permission will be obtained from the selected HLl's authorities to recruit the participants.

\section{Phase 1}

The potential participants were recruited and invited to complete an online questionnaire administered using the official online survey questionnaire. Those who completed the survey were asked to a specific venue in their institution for anthropometric measurement, blood pressure, and blood sample investigation (to refer Figure1). 


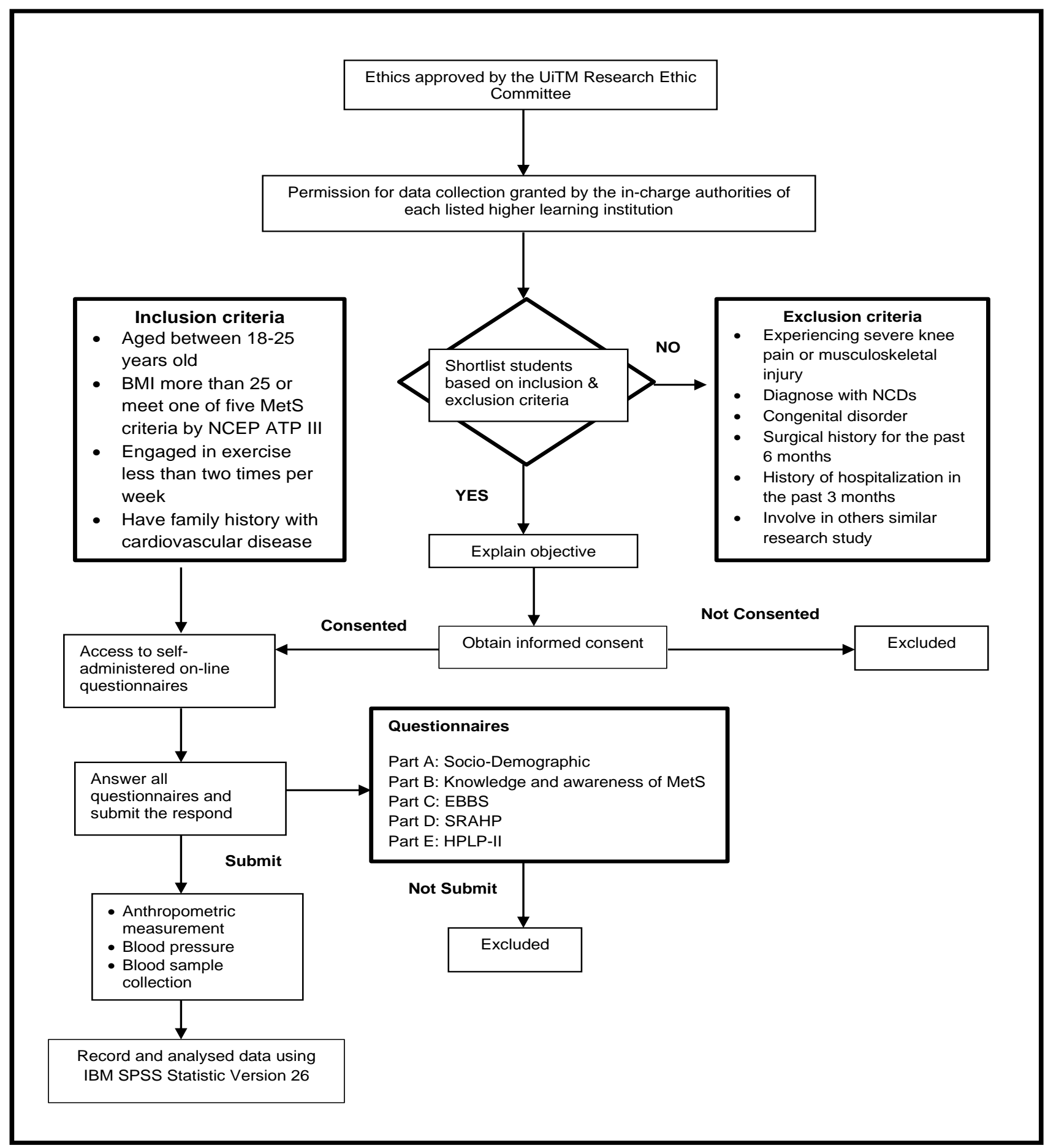

Figure 1: Data Collection Process for Phase 1

\section{Phase 2}

Verbal and written consent was obtained from the participants in harmony with the Helsinki declaration, and the study details are explained. The data will be collected during the pre-and post- intervention of 12-week health-promoting lifestyle modification behaviour. The data collection method will be divided into three phases: pre-intervention (baseline assessment), intervention and post-intervention (final 
assessment). Follow-up will be added as an additional phase and will be conducted one month after intervention completion (to refer Figure 2).

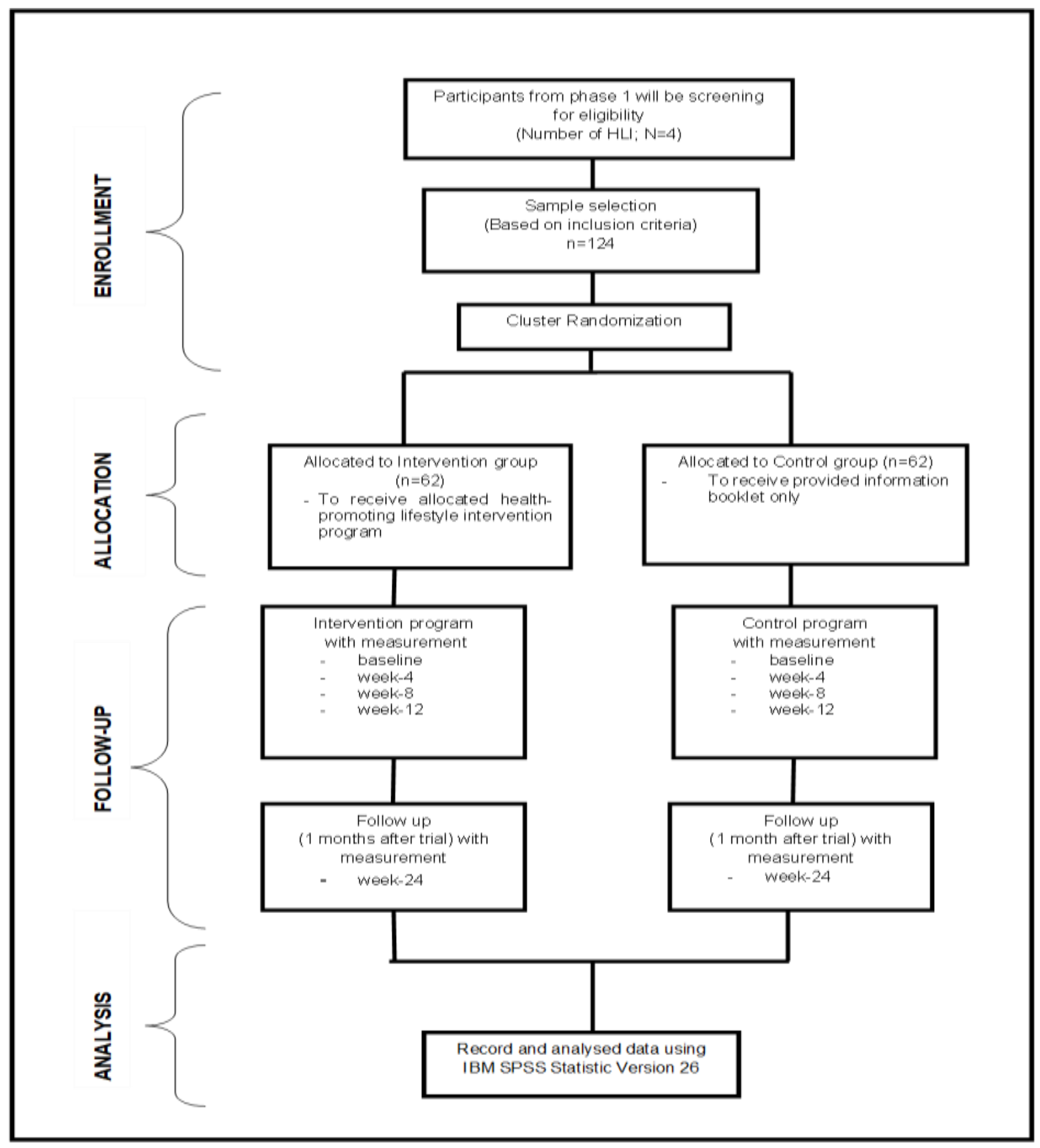

Figure 2: Data Collection Process for Phase 2

\subsection{Data Analysis}

According to their group assignment, the participants were analyzed based on the intention-to-treat principle to provide an unbiased estimate of the intervention's efficacy, maintain reliability and validity, and prevent randomization errors (McCoy, 2017). 


\section{Phase 1}

Descriptive statistics were used to summarize participants' health and demographic characteristics. A self-administered questionnaire were analyzed using Chi-square for categorical variables. In contrast, as appropriate, continuous variables were assessed using Pearson Correlation Coefficient, independent t-test and Analysis of Variance (ANOVA) (for normal distribution of data). A $p$ value $<0.05$ were considered as statistically significant.

\section{Phase 2}

Data was coded and analyzed using SPSS version 24.0. Comparisons between the intervention group and the control group were performed using univariate and multivariable methods. Outcome variables at baseline and 3 months post-test were used to test the hypotheses in association with the covariates and confounding variables. To evaluate effects in each group, repeated measure Analysis of Variance (ANOVA) was used. Mixed design ANOVA performed to determine the effects between the groups. The significance level for all analyses was set at $p<0.05$.

\section{Expected outcome/ Summary}

The finding of this study may indicate the development of new conceptual framework related to lifestyle behaviour intervention on management of metabolic syndrome among tertiary education population in order to prevent and reduce the prevalence of cardiovascular risk factor in the future. Furthermore, a new lifestyle modification intervention program by mean of an all-inclusive perspective and holistic nature as the finding will make it an accommodating approach related lifestyle behaviour of higher education population in order to manage metabolic syndrome generally among young adult with potential to reduce the risk to develop non-communicable disease. In addition, this fundamental of this study will provide as a novel material that can be used as a guideline and references to the health-care provider with MetS issue. It also can be as new findings or references for the Asian and international health care practices.

\section{Acknowledgement}

Authors would like to thank Institute of Research Management Center (RMC) of Universiti Teknologi MARA for funding the research. Grant No: 600-RMC/GPK 5/3 (064/2020)

\section{Paper Contribution to Related Field of Study}

This study can promote an optimize healthy lifestyle behaviour among young adults and potentially contribute to programs and policies guideline to reduce the risk of developing non-communicable diseases in the future. The finding from this study will create awareness among young adults regarding dyslipidemia and MetS as risk factors in developing CVDs by increasing knowledge, confidence and skills in order to develop longevity habit and promote health behaviour towards healthy lifestyle. As been mention before, the field of the study still not been covered in depth and not fully explored in Malaysia. Hence, the finding from this study will provide novel material and baseline information to improve the guideline and management performance especially among the target population. The information from the finding of this study may also contribute as baseline information for the ministry and provide a medium especially for nursing profession in delivering an optimum health promotion and expand professional scope into preventive measured intervention across the population.

\section{References}

Abdullah, M.F., Nazarudin, M.N., Saadan, R. Wan Pa, W.A.M., \& Abdul Razak, M.R. (2018). Benefits and Barriers of Physical Activities among Technical University Students. Journal of Advanced Research in Social and Behavioural Sciences, 13(1), 1-8. ISSN: 2462-1951

Anjali, \& Sabharwal, M. (2015). Journal of Nutrition \& Food Sciences Effectiveness of Lifestyle Interventions among College Students: An Overview. Journal of Nutrition \& Food Sciences, 5(3). https://doi.org/10.4172/2155-9600.1000363

Azami, G., Kim, L.S., Shariff G. S., Said, M. S., Sanaz, A., Mosayeb M., \& Hamid, T. (2018). Effect of a Nurse-Led Diabetes Self-Management Education Program on Glycosylated Hemoglobin among Adults with Type 2 Diabetes. Journal of Diabetes Research, 2018. https://doi.org/10.1155/2018/4930157

Becker, H. (1993). Self-rated abilities for health practices: A health self-efficacy measure.

The Journal of Health Behavior, Education \& Promotion, 17(3), 42-50

Brandão, M. P., Pimentel, F. L., \& Cardoso, M. F. (2011). Impact of academic exposure on health status of university students. Revista de saude publica, 45(1), 49-58. https://doi.org/10.1590/s0034-89102011000100006

Chilton, J.M., Gosselin, K.P., \& Haas, B.K. (2018). Development of the Self-Rated Abilities for Health Practices-Adolescent Version: A Self-Efficacy Measure. Journal of Nursing Measurement, 26(1), 134-141.doi: 10.1891/1061-3749.26.1.134. PMID: 29724284.

Cook, S., Auinger, P., \& Huang, T. T. (2009). Growth curves for cardio-metabolic risk factors in children and adolescents. The Journal of pediatrics, 155(3), S6.e15-S6.e26. https://doi.org/10.1016/j.jpeds.2009.04.051

Huff,T, Boyd, B., \& Jialal I. Physiology, Cholesterol. 2020 Aug 24. In: StatPearls [Internet]. Treasure Island (FL): StatPearls Publishing; 2021 Jan-. PMID: 29262185. 
Gebreyes, Y. F., Goshu, D. Y., Geletew, T. K., Argefa, T. G., Zemedu, T. G., Lemu, K. A., et al. (2016). A review of metabolic syndrome research in Malaysia. Medical Journal of Malaysia, $71,20-28$.

Haney, E.M., Huffman, L.H., Bougatsos, C., Freeman, M., Steiner, R.D., \& Nelson, H.D. (2007). Screening and treatment for lipid disorders in children and adolescents: systematic evidence review for the US Preventive Services Task Force. Pediatrics, 120(1), 189-214.

Ibrahim, M. M., Rahman, N. A. A., Rahman, N. I. A., \& Haque, M. (2016). Knowledge, Attitude and Practice of Malaysian Public University Students on Risk Factors for Cardiovascular Diseases. Journal of Applied Pharmaceutical Science ,6 (02), 056-063. https://doi.org/10.7324/JAPS.2016.60208

Kim, M.J., \& Kim, Y.J. (2018). What Causes Health Promotion Behaviors in College Students? The Open Nursing Journal, 12 (106-115). DOI: $10.2174 / 1874434601812010106$

Kolovou, G. D., Anagnostopoulou, K. K., \& Cokkinos, D. V. (2005). Pathophysiology of dyslipidaemia in the metabolic syndrome. Postgraduate medical journal, 81(956), 358-366. https://doi.org/10.1136/pgmj.2004.025601

Ranasinghe, P., Mathangasinghe, Y., Jayawardena, R., Hills, A. P., \& Misra, A. (2017). Prevalence and trends of metabolic syndrome among adults in the Asia-pacific region: A systematic review. BMC Public Health, 17(1), 1-9. https://doi.org/10.1186/s12889-017-4041-1

Kuan, G., Yee, C.K., Abdullah, N., \& Li, M.T.E. (2019). Psychometric properties of the health-promoting lifestyle profile II: cross-cultural validation of the Malay language version. BMC Public Health Journal. 19 (751). https://doi.org/10.1186/s12889-019-7109-2

Monnerie, S., Comte, B., Ziegler, D., Morais, J. A., Pujos-Guillot, E., \& Gaudreau, P. (2020). Metabolomic and Lipidomic Signatures of Metabolic Syndrome and its Physiological Components in Adults: A Systematic Review. Scientific Reports, 10(1), 1-13. https://doi.org/10.1038/s41598-019-56909-7

Peltzer, K., \& Pengpid, S. (2018). Prevalence, risk awareness and health beliefs of behavioural risk factors for cardiovascular disease among university students in nine ASEAN countries. BMC public health, 18(1), 237. https://doi.org/10.1186/s12889-018-5142-1

Rifin, H. M., Gayle, T., Lourdes, R., Liana, N., Majid, A., Akmal, H., \& Hamid, A. (2018). Hypercholesterolemia Prevalence, Awareness, Treatment and Control among Adults in Malaysia: The 2015 National Health and Morbidity Survey, Malaysia. Global Journal of Health Science 10(7), 11-23. https://doi.org/10.5539/gjhs.v10n7p11

Saboya, P. P., Bodanese, L. C., Zimmermann, P. R., Gustavo, A. D., Macagnan, F. E., Feoli, A. P., \& Oliveira, M. D. (2017). Lifestyle Intervention on Metabolic Syndrome and its Impact on Quality of Life: A Randomized Controlled Trial. Arquivos brasileiros de cardiologia, 108(1), 60-69. https://doi.org/10.5935/abc.20160186

Saklayen, M. G. (2018). The Global Epidemic of the Metabolic Syndrome. Current Hypertension Reports, 20(2), 1-8. https://doi.org/10.1007/s11906-018-0812-z

Yahia, N., Brown, C., Rapley, M., \& Chung, M. (2014). Assessment of college students' awareness and knowledge about conditions relevant to metabolic syndrome. Diabetology and Metabolic Syndrome, 6(1), 1-15. https://doi.org/10.1186/1758-5996-6- 111

Zhang, P., Xing, F.M., Li, C.Z., Lan, W.F. , \& Zhang, X.L. (2018). Effects of a nurse-led transitional care program on readmission, self-efficacy to implement health promoting behaviors, functional status and life quality among Chinese patients with coronary artery disease: a randomized controlled trial. Journal of Cardiovascular Nursing. 27 (56), 969-979 